\title{
A Pleasant Sensation Evoked by Knee or Hand Icing Influences the Effect on Pain Intensity in Patients After Total knee Arthroplasty: A Prospective, Randomized, Cross-Over Study
}

This article was published in the following Dove Press journal:

Journal of Pain Research

\author{
Tomohiko Nishigami (D) \\ Satoshi Nakao ${ }^{2}$ \\ Hiroshi Kondo ${ }^{3}$ \\ Shota Oda $\mathbb{D i}^{3}$ \\ Akira Mibu (D) ${ }^{1}$ \\ 'Department of Physical Therapy, Faculty \\ of Health and Welfare, Prefectural \\ University of Hiroshima, Hiroshima 723- \\ 0053, Japan; ${ }^{2}$ Department of \\ Rehabilitation, Aihotto Home-Visit \\ Nursing Station Ainan, Ehime 798-4I3I, \\ Japan; ${ }^{3}$ Department of Rehabilitation \\ Center, Kochi Medical School Hospital, \\ Kochi 783-8505, Japan
}

Purpose: Cold therapy on the operated area after surgery is often used as an analgesic and to reduce pain, swelling, and increase range of motion. However, evidence to support the results of cold therapy is still scarce and the mechanism underlying its effectiveness remains unclear. The present study aimed to investigate whether a pleasant sensation evoked by icing the treated knee or a site distant from the treated site (the hand) influenced the acute effect on pain intensity in patients who have undergone total knee arthroplasty (TKA).

Patients and methods: A total of 37 patients with knee OA who underwent TKA were enrolled in this study. This prospective, randomized, cross-over study was performed for 2 days consecutively between days 8 and 15 postoperatively. Cold pack was placed on the anterior surface of the treated knee and palm for 10 mins, respectively. The main primary outcomes were the intensity of knee pain during maximal passive knee flexion.

Results: The two-way ANOVA showed significance only in the main effect of a pleasant sensation $(F=11.3, p=0.001)$, but not in the icing site $(F=0.005, p=0.94)$ and interaction $(\mathrm{F}=0.65, \mathrm{p}=0.42)$.

Conclusion: This study shows that a pleasant sensation evoked by knee or hand icing influenced the effect on pain intensity during maximal knee flexion in patients after TKA. Even if knee icing has no effect on pain and evokes no pleasant sensation, it may be worthwhile to conduct hand icing to reduce pain.

Keywords: total knee arthroplasty, Icing, pleasant sensation, descending pain inhibition system

\section{Introduction}

Total knee arthroplasty (TKA) has played an important role in the management of end-stage knee osteoarthritis (OA). ${ }^{1}$ Range of motion (ROM) is one of the indicators of successful $\mathrm{TKA}^{2}$ and is directly related to function. ${ }^{3}$ Knee joint kinematics data have demonstrated that $110^{\circ}$ of knee flexion is required to achieve rehabilitation of the knee movement. ${ }^{3}$ Therefore, early recovery of ROM is crucial after TKA, and adequate analgesia during ROM exercises is necessary to achieve this aim.

Cold therapy on the operated area after surgery is often used as an analgesic ${ }^{4,5}$ and to reduce pain, ${ }^{6,8,9}$ swelling, ${ }^{7}$ and increase ROM. ${ }^{10,11}$ The effectiveness of analgesia induced by cold therapy, such as cryotherapy, ice pack, and ice massage,
Correspondence: Tomohiko Nishigami Department of Nursing and Physical Therapy, Konan Woman's University, 6-2-23, Morikita-machi, Higashinada-ku, Kobe 658-000I, Japan

Tel +81784133648

Fax +81784133742

Email t-nishi@konan-wu.ac.jp 
has been reported to reduce tissue temperature ${ }^{12,13}$ and nerve conduction velocity. ${ }^{14-16}$ However, evidence to support the results of cold therapy is still scarce ${ }^{17,18}$ and the mechanism underlying its effectiveness remains unclear.

Pleasant sensation such as music, ${ }^{19,20}$ pictures, ${ }^{21}$ odors, ${ }^{22}$ or hypnosis ${ }^{23}$ have achieved a reduced response to pain stimulation. The effects of such pleasant sensations were partly mediated by activating the descending modulation pain pathway of the spinal $\operatorname{cord}^{20,24}$ and opioid analgesia-related brain regions. ${ }^{25}$ It is well known that a pleasant sensation is evoked by cooling. The pleasantness of cold stimuli on capsaicin-treated skin has been associated with the activation of the prefrontal cortex and periaqueductal gray matter that constitutes the descending pain inhibition-related area. ${ }^{26}$ Cold application to the unaffected skin on the contralateral side has been reported to reduce pain induced by capsaicin in healthy volunteers. ${ }^{27,28}$ These findings might indicate that the efficacy of cooling may be produced via the descending pain inhibition system as well as cooling-mediated decreased peripheral nociceptive input. However, these studies were performed in healthy volunteers; therefore, it is unclear whether the response to cooling may be influenced by the existence of pleasant sensations in patients after surgery. We hypothesized that cold application to a site distant from the treated knee would be as effective for pain reduction as cold application directly to the treated knee and inducing a pleasant sensation would influence the efficacy of pain reduction by icing. We investigated whether a pleasant sensation evoked by icing the treated knee or a site distant from the treated site (the hand) influenced the acute effect on pain intensity during maximal knee flexion in patients who have undergone TKA.

\section{Materials and Methods}

\section{Participants}

A total of 37 patients with knee OA who underwent TKA were enrolled in a university hospital and a general hospital. For a two-treatment crossover design, we assumed an alpha error of 0.05 , a statistical power of 0.95 , and a treatment effect of $19.9 \mathrm{~mm}^{29}$ on a $100-\mathrm{mm}$ pain intensity visual analog scale (VAS), with an estimated standard deviation of $20 \mathrm{~mm}$, a within-subject correlation of 0.50 , and a necessary sample size of $n=27$. As this study was conducted in a clinical setting with more experimental noise than a laboratory setting, we assumed a lower effect size and a need for more participants. Therefore, we decided on $\mathrm{n}=37$ as the sample size.

The inclusion criteria were patients who underwent primary TKA, $\geq 40$ years of age, and exhibiting ambulation before surgery. Exclusion criteria were revision TKA, nonambulatory before surgery, presence of severe inflammation, and evidence of deep vein thrombosis after surgery.

This study was conducted in compliance with the Declaration of Helsinki. This study followed the CONSORT recommendations concerning randomized trial reporting. This trial is registered with UMIN Clinical Trial Registry: UMIN000024596.

\section{Surgical and Postoperative Procedures}

TKA was conducted using a minimally invasive surgical approach with a posterior-stabilized prosthesis. A midline skin incision was made via a medial mini-midvastus arthrotomy, and the patella was subluxated laterally but not everted.

All patients received epidural anesthesia during surgery and patient-controlled epidural analgesia for $48 \mathrm{~h}$ postoperatively. Postoperative rehabilitation included strengthening and range of motion exercises and mobilization with a high walker from day 1 postoperatively. Postoperative analgesics were standardized for all patients. Nonsteroidal anti-inflammatory drugs (Loxoprofen sodium) were administered postoperatively twice a day for 4 weeks. The patients were discharged or transferred from the hospital after at least 3 weeks postoperatively. Continuous flow cold compression therapy was provided to all participants using the Icing System CE4000 (Nippon Sigmax Co., Ltd.) from the day of surgery until day 2 postoperatively.

Knee icing was offered to subjects from day 3 to day 7 as usual care.

\section{Intervention}

This prospective, randomized, cross-over study was performed for 2 days consecutively between days 8 and 15 postoperatively (Figure 1). This study began 8 days after the operation on the basis of the fact that the effect of inflammation was intense 1 week postoperatively, and the effect of icing could not be adequately evaluated. The order of treatments was randomized using block randomization. The patients were made to rest in the supine position with pillows under their head and knees during both treatments. Icing was conducted using an aqua gel cold pack (Hisamitsu Pharmaceutical Co., Inc. Tokyo, Japan). 


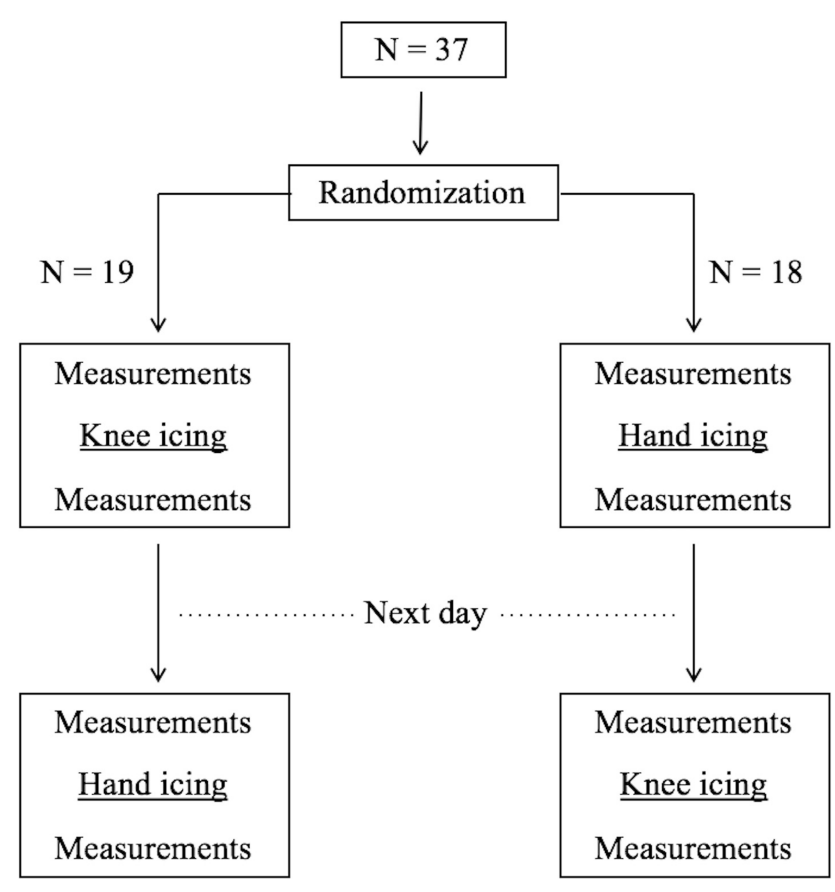

Figure I Trial profile.

The cold pack was covered with a cloth to protect the skin from potential thermal damage and placed on the anterior surface of the treated knee or palm on separate days, respectively. The cold pack temperature before treatment was $1-1.5^{\circ} \mathrm{C}$. Patients were instructed to apply the cold pack for $10 \mathrm{~min}$.

\section{Outcome Measures}

All assessments were performed by physical therapists with an average of 7 years of working experience. The primary outcomes were the intensity of knee pain during maximal passive knee flexion that was measured by the physical therapist. The outcome assessor was blind to the intervention assignment. The angle of passive knee flexion was measured using a universal goniometer. Patients were asked about the pain intensity after maintaining maximal knee flexion for $10 \mathrm{~s}$. Pain intensity was measured using VAS, ranging from $0 \mathrm{~mm}$ (no pain) to $100 \mathrm{~mm}$ (worst pain). Pain intensity was assessed before and after icing. The angle of maximal passive knee flexion after icing was set to the same angle before icing by the same physiotherapist. This method, in which the physiotherapist measured passive knee flexion using a universal goniometer, has high intra-tester and intra-day reliability. ${ }^{30}$ Change in score induced by icing was calculated by subtracting pain intensity measured before icing from that measured after icing. Immediately after each icing, the patients were asked, "Did you feel a pleasant sensation during icing?" and they were classified into two groups based on whether they did or did not experience a pleasant sensation evoked by icing.

\section{Statistical Analysis}

All statistical analyses were performed using the Statistical Package for Social Sciences Version 22 (IBM SPSS Statistics for Windows, Version 22.0; IBM Corp., Armonk, NY, USA). Data distribution was tested for homoscedasticity using the Levene's test. The differences in knee pain intensity measured before knee and hand icing, after knee and hand icing, and before and after treatment for knee and hand icing were assessed using paired t-tests, respectively. Moreover, the differences in pain intensity score change between knee and hand icing were assessed using paired t-tests. A two-way factorial analysis of variance (ANOVA) was used to evaluate the effect on the icing site (knee, hand) and effect of the sensation (pleasant, no pleasant) in pain intensity score change. The sphericity assumption was analyzed using Mendoza's multi-sample sphericity test. Value of $p<0.05$ was considered statistically significant. Effect size of the icing site, sensation, and interaction were calculated on the basis of $\eta^{2}$ (a large effect was defined as $>0.14$, a moderate effect between 0.06 and 0.14 , and a small effect $<0.06$ ).

\section{Results}

Table 1 summarizes the patients' characteristics. A pleasant sensation was evoked in 24 patients (64.8\%) during knee icing and in $26(70.2 \%)$ during hand icing. Eleven patients (29.7\%) felt a pleasant sensation during knee icing but no pleasant sensation during hand icing, 13 (35.1\%) felt a pleasant sensation during hand icing but no pleasant sensation during knee icing, and 13 (35.1\%) felt a pleasant sensation during both knee and hand icing.

No significant difference was found between pain intensity measured before knee icing $(61.3 \pm 17.8 \mathrm{~mm})$ and hand

Table I Demographic and Clinical Information

\begin{tabular}{|l|l|}
\hline Characteristics & Mean (SD) or N (\%) \\
\hline Gender (female) & $32(86.4 \%)$ \\
Age (years) & $75.3(5.9)$ \\
Pleasant sensation during knee (number) & $24(64.8 \%)$ \\
Pleasant sensation during hand (number) & $26(70.2 \%)$ \\
ROM before knee icing (degree) & $102.4(13.1)$ \\
ROM before hand icing (degree) & $105.0(12.4)$ \\
\hline
\end{tabular}


Table 2 Pain Intensity Before and After Knee and Hand Icing, and Change Score in Knee and Hand lcing

\begin{tabular}{|l|l|l|l|l|}
\hline & Knee & Hand & $\begin{array}{l}\text { Mean Difference } \\
(95 \% \mathbf{C l})\end{array}$ & p value \\
\hline Before icing & $61.3 \pm 17.8$ & $63.7 \pm 16.1$ & $-2.4(-6.6$ to 1.7$)$ & 0.25 \\
After icing & $46.4 \pm 19.8$ & $48.9 \pm 24.6$ & $-2.5(-11.3$ to 6.2$)$ & 0.55 \\
Change & -14.9 & -14.7 & $-0.16(-9.3$ to 9.0$)$ & 0.97 \\
score & \pm 21.7 & \pm 22.4 & & \\
\hline
\end{tabular}

icing $(63.7 \pm 16.1 \mathrm{~mm}$; difference, $-2.4 ; 95 \%$ confidence interval $[\mathrm{CI}],-6.6-1.7 ; \mathrm{p}=0.25)$ and between that measured after knee icing $(46.4 \pm 19.8 \mathrm{~mm})$ and hand icing $(48.9 \pm 24.6 \mathrm{~mm}$; difference, $-2.5 ; 95 \% \mathrm{CI},-11.3-6.2 ; \mathrm{p}=$ 0.55 ; Table 2). The pain intensity reduced from $61.3 \pm$ $17.8 \mathrm{~mm}$ before knee icing to $46.4 \pm 19.8 \mathrm{~mm}$ after knee icing (difference, 14.9; 95\% CI, 7.6-22.2; $\mathrm{p}=0.0002$ ) and from $63.7 \pm 16.1 \mathrm{~mm}$ before hand icing to $48.9 \pm 24.6 \mathrm{~mm}$ after hand icing (difference, 14.7; 95\% CI, 7.1-22.3; $P=$ 0.0003 , Figure 2). There was no significant difference in pain intensity score change between knee icing $(-14.9 \pm$ $21.7 \mathrm{~mm})$ and hand icing $(-14.7 \pm 22.4 \mathrm{~mm}$; difference, $-0.16 ; 95 \%$ CI, $-9.3-9.0 ; \mathrm{p}=0.97$; Table 2). The two-way ANOVA showed significance only in the main effect of a pleasant sensation $\left(F=11.3, p=0.001, \eta^{2}=0.14\right)$ but not in the icing site $\left(\mathrm{F}=0.005, \mathrm{p}=0.94, \eta^{2}=0.001\right)$ and interaction $\left(\mathrm{F}=0.65, \mathrm{p}=0.42, \eta^{2}=0.01\right.$, Figure 3$)$. Mendoza's multi-sample sphericity test revealed that the sphericity assumption was satisfied.

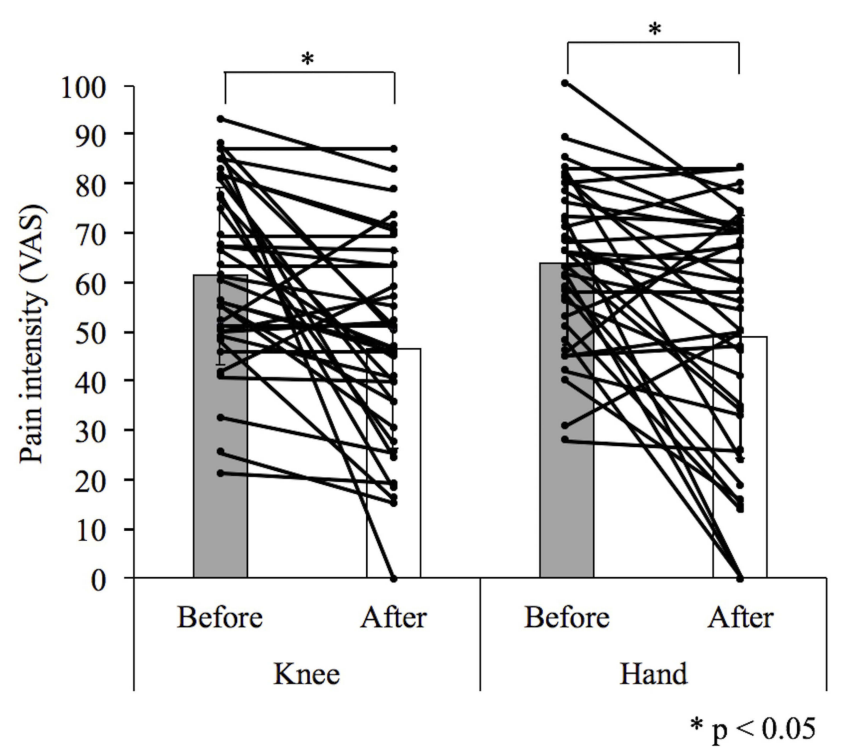

Figure 2 Comparison of the differences between before and after treatment in knee or hand icing.

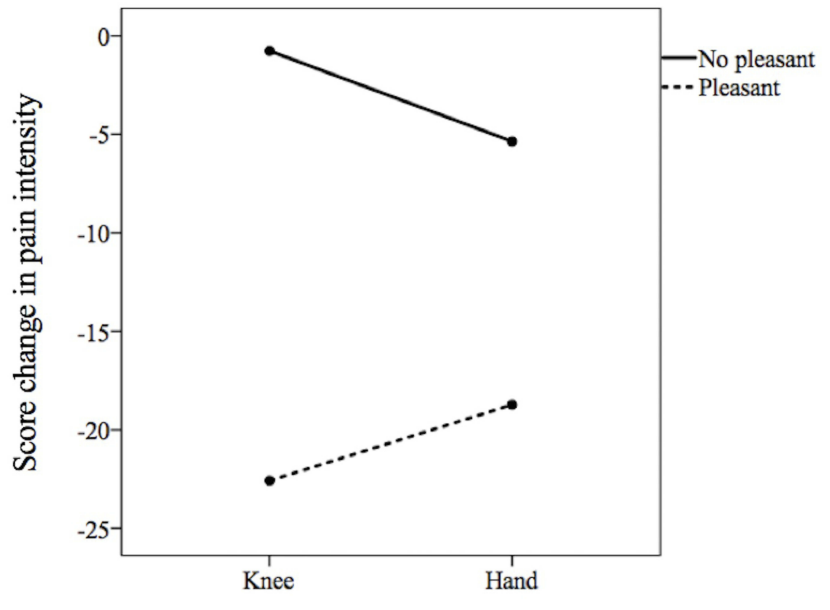

Figure 3 Comparisons of the differences in the change score of pain intensity on the icing site between pleasant versus no pleasant sensation.

Notes: The two-way analysis of variance showed significance only in the main effect of a pleasant sensation $(p=0.00 \mathrm{I})$, but not the icing site $(p=0.94)$ and interaction $(p=0.42)$.

\section{Discussion}

Our findings showed that both knee and hand icing had an effect on pain intensity during maximal knee flexion, and the effect of icing was influenced by the existence of a pleasant sensation and not the icing site. This was a randomized cross-over study in which the patients received knee or hand icing on two consecutive days. The sequence of testing was randomized to control for an order effect. Moreover, there was no difference in pain intensity before knee and hand icing. This result suggested that there was no carry-over effect.

The present study result that knee or hand icing had an acute effect on pain intensity during maximal knee flexion is inconsistent with the results of a previous report stating that knee or elbow joint icing for $30 \mathrm{~min}$ after TKA had no acute effect on knee extension strength or knee pain. ${ }^{31}$ We evaluated pain intensity during maximal knee flexion, but Holm et $\mathrm{al}^{31}$ evaluated pain intensity during knee extension strength and knee pain, and our mean pain intensity score before treatment was higher than that reported by Holm et al ${ }^{31}$ Patients with higher pain intensity score may react more easily to treatment than those with lower pain intensity. Moreover, Holm et $\mathrm{al}^{31}$ suggested that the reason why knee icing had no effect on knee pain was insufficient cooling. In the present study, the cold pack temperature before treatment was $1-1.5^{\circ} \mathrm{C}$, and this temperature may have been enough to cool the skin.

A surprising result in our study was the finding of a similar effect in knee and hand icing. Several studies have stated that the effects of cold application were produced by a change in the peripheral tissue, such as 
decreased tissue temperature ${ }^{12,13}$ and sensory fiber conduction. $^{14-16}$ However, these reasons cannot only explain that hand icing reduced pain intensity. A possible reason is that hand icing activated the descending pain inhibition system and, as a result, pain during maximal knee flexion may be reduced. Diffuse noxious inhibitory controls (DNIC), which constitute one of the main descending pain inhibition systems, are supraspinal mechanisms that control pain via the subnucleus reticularis, ${ }^{32}$ which suppresses spinal neuron activity and reduces pain by nociceptive stimulation. Noxious cold application to the arm has been reported to reduce response to nociceptive stimulation in the leg. ${ }^{33,34}$ However, our result showed that a pleasant sensation led to a higher reduction in pain than no pleasant sensation, in which case DNIC might not influence the efficacy of icing. Therefore, we hypothesized that a pleasant sensation due to icing may be as effective as other sensations, such as music, ${ }^{19,20}$ pictures, ${ }^{21}$ odors. ${ }^{22}$ Mohr et $\mathrm{al}^{26}$ reported that cold stimuli to capsaicin-treated skin evoked a pleasant sensation and the sensation was correlated with activation of the descending pain inhibition system-related cortical areas, but the untreated skin elicited an unpleasant perception. This inconsistence in response to icing conducted to a distant site may result from a difference in experimental setting (laboratory versus clinical setting).

This study began 8 days postoperatively. Icing immediately after surgical intervention could be an effective strategy. However, peak levels of serum C-reactive protein (an inflammatory marker), are usually observed on day 2 or 3 postoperatively, and these levels rapidly decline over the rest of the first week postoperatively. ${ }^{35,36}$ In our view, a stable peripheral condition of the patient can be considered the most appropriate period to perform this study to avoid the risk of introduction of bias during periods of intense inflammation.

Our data suggested a new clinical implication. In approximately one-third of the patients, it is likely that cold application to the hand resulted in more reduced pain than that to the knee. Several studies have reported that cold application to the knee was not effective in pain reduction. ${ }^{17,37,38}$ Even if knee icing has no effect on pain and evokes no pleasant sensation, it might be worthwhile to conduct hand icing to reduce pain during maximal knee flexion after TKA.

The current study has some limitations. First, there might be potential bias because neither the patients nor the outcome assessors could be blinded due to the nature of the intervention. Second, this study did not include assessment of skin temperature and nerve conduction velocity (NCV) in the sensory nerves. Reduction in sensory NCV was associated with an increase in the threshold and tolerance of pain after cooling. ${ }^{14}$ Therefore, we cannot conclude that the efficacy of knee icing was produced by reduction in NCV or activation of a pleasant sensation via the descending pain inhibition system. Third, our findings may not be generalizable to patients after revision TKA, or those with severe inflammation and other cooling methods, such as continuous cryotherapy and ice massage. Fourth, the other pleasant sensations, such as music and pictures, were not evaluated in this study. Therefore, it is unclear whether a pleasant sensation evoked by icing has a specific effect on pain intensity. It is possible that the pleasant sensations evoked by other modalities are as effective as cold application for pain intensity after TKA. Fifth, the patients were stratified on the basis of the "pleasant" sensation of icing. This is a subjective measure because the magnitude of the "pleasant" response cannot be quantified.

\section{Conclusion}

This study shows that a pleasant sensation evoked by knee or hand icing influenced the effect on pain intensity during maximal knee flexion in patients after TKA. Hand icing may be an optional treatment for patients after undergoing TKA.

\section{Ethics Approval and Informed Consent}

Ethics approval was obtained from the institutional ethics committee of Konan Women's University. Written informed consent was obtained from all subjects prior to the study.

\section{Data Sharing Statement}

The datasets used and analyzed during the current study are available from the corresponding author.

\section{Acknowledgments}

We thank Tomonari Okada and Yoshiteru Akezaki for help with date collecting.

\section{Author Contributions}

All authors contributed to data analysis, drafting or revising the article, gave final approval of the version to be published, and agree to be accountable for all aspects of the work. 


\section{Disclosure}

The authors report no conflicts of interest in this work.

\section{References}

1. Felson DT, Lawrence RC, Hochberg MC, et al. Osteoarthritis: new insights. Part 2: treatment approaches. Ann Intern Med. 2000;133 (9):726-737.

2. MA R, Campbell ED. Effect of range of motion on the success of a total knee arthroplasty. $J$ Arthroplasty. 1987;2(2):95-97. doi:10.1016/S0883-5403(87)80015-3

3. Rowe PJ, Myles CM, Walker C, et al. Knee joint kinematics in gait and other functional activities measured using flexible electrogoniometry: how much knee motion is sufficient for normal daily life? Gait Posture. 2000;12(2):143-155. doi:10.1016/S0966-6362(00)00060-6

4. Martin SS, Spindler KP, Tarter JW, et al. Does cryotherapy affect intraarticular temperature after knee arthroscopy? Clin Orthop Relat Res. 2002;400:184-189. doi:10.1097/00003086-200207000-00023

5. Woolf SK, Barfield WR, Merrill KD, et al. Comparison of a continuous temperature-controlled cryotherapy device to a simple icing regimen following outpatient knee arthroscopy. J Knee Surg. 2008;21(1):15-19. doi:10.1055/s-0030-1247786

6. Kullenberg B, Ylipaa S, Soderlund K, et al. Postoperative cryotherapy after total knee arthroplasty: a prospective study of 86 patients. $J$ Arthroplasty. 2006;21(8):1175-1179.

7. Schroder D, Passler HH. Combination of cold and compression after knee surgery. A prospective randomized study. Knee Surg Sports Traumatol Arthrosc. 1994;2(3):158-165. doi:10.1007/BF01467918

8. Singh H, Osbahr DC, Holovacs TF, et al. The efficacy of continuous cryotherapy on the postoperative shoulder: a prospective, randomized investigation. $J$ Shoulder Elbow Surg. 2001;10(6):522-525. doi: $10.1067 / \mathrm{mse} .2001 .118415$

9. Webb JM, Williams D, Ivory JP, et al. The use of cold compression dressings after total knee replacement: a randomized controlled trial. Orthopedics. 1998;21(1):59-61. doi:10.3928/0147-7447-1998010114

10. Cohn BT, Draeger RI, Jackson DW. The effects of cold therapy in the postoperative management of pain in patients undergoing anterior cruciate ligament reconstruction. Am J Sports Med. 1989;17 (3):344-349. doi:10.1177/036354658901700306

11. Levy AS, Marmar E. The role of cold compression dressings in the postoperative treatment of total knee arthroplasty. Clin Orthop Relat Res. 1993;297:174-178.

12. Knight KL. Cryotherapy in Sport Injury Management. Champaign, IL: Human Kinetics; 1995.

13. Nadler SF, Weingand K, Kruse RJ. The physiological basis and clinical applications of cryotherapy and thermotherapy for the pain practitioner. Pain Physician. 2004;7(3):395-399.

14. Algafly AA, George KP. The effect of cryotherapy on nerve conduction velocity, pain threshold and pain tolerance. $\mathrm{Br} J$ Sports Med. 2007;41(6):365-369. doi:10.1136/bjsm.2006.031237

15. Chesterton LS, Foster NE, Ross L. Skin temperature response to cryotherapy. Arch Phys Med Rehabil. 2002;83(4):543-549. doi:10.1053/apmr.2002.30926

16. Herrera E, Sandoval MC, Camargo DM, et al. Motor and sensory nerve conduction are affected differently by ice pack, ice massage, and cold water immersion. Phys Ther. 2010;90(4):581-591. doi:10.2522/ptj.20090131

17. Markert SE. The use of cryotherapy after a total knee replacement: a literature review. Orthop Nurs. 2011;30(1):29-36. doi:10.1097/ NOR.0b013e318205749a

18. McMaster W, Liddle S. Cryotherapy influence on posttraumatic limb edema. Clin Orthop Relat Res. 1980;150:283-287.
19. Roy M, Peretz I, Rainville P. Emotional valence contributes to music-induced analgesia. Pain. 2008;134(1-2):140-147. doi:10.10 16/j.pain.2007.04.003

20. Roy M, Lebuis A, Hugueville L, et al. Spinal modulation of nociception by music. Eur J Pain. 2012;16(6):870-877. doi:10.1002/ ejp.2012.16.issue-6

21. Meagher MW, Arnau RC, Rhudy JL. Pain and emotion: effects of affective picture modulation. Psychosom Med. 2011;63(1):79-90. doi:10.1097/00006842-200101000-00010

22. Villemure C, Slotnick BM, Bushnell MC. Effects of odors on pain perception: deciphering the roles of emotion and attention. Pain. 2003;106(1-2):101-108. doi:10.1016/S0304-3959(03)00297-5

23. Rainville P, Bao QVH, Chretien P. Pain-related emotions modulate experimental pain perception and autonomic responses. Pain. 2005;118(3):306-318. doi:10.1016/j.pain.2005.08.022

24. Rhudy JL, Williams AE, McCabe KM, et al. Affective modulation of nociception at spinal and supraspinal levels. Psychophysiology. 2005;42(5):579-587. doi:10.1111/j.1469-8986.2005.00313.x

25. Kut E, Candia V, von Overbeck J, et al. Pleasure-related analgesia activates opioid-insensitive circuits. J Neurosci. 2011;31 (11):4148-4453. doi:10.1523/JNEUROSCI.3736-10.2011

26. Mohr C, Leyendecker S, Mangels I, et al. Central representation of cold-evoked pain relief in capsaicin induced pain: an event-related fMRI study. Pain. 2008;139(2):416-430. doi:10.1016/j.pain.2008.05. 020

27. Pud D, Sprecher E, Yarnitsky D. Homotopic and heterotopic effects of endogenous analgesia in healthy volunteers. Neurosci Lett. 2005;380(3):209-213. doi:10.1016/j.neulet.2005.01.037

28. Pud D, Yarnitsky D, Eisenberg E, et al. Effects of cold stimulation on secondary hyperalgesia (HA) induced by capsaicin in healthy volunteers. Exp Brain Res. 2006;170(1):22-29. doi:10.1007/s00221005-0185-9

29. Tubach F, Ravaud P, Baron G, et al. Evaluation of clinically relevant changes in patient reported outcomes in knee and hip osteoarthritis: the minimal clinically important improvement. Ann Rheum Dis. 2005;64(1):29-33. doi:10.1136/ard.2004.022905

30. Jakobsen TL, Christensen M, Christensen SS, et al. Reliability of knee joint range of motion and circumference measurements after total knee arthroplasty: does tester experience matter? Physiother Res Int. 2010;15(3):126-134. doi:10.1002/pri.450

31. Holm B, Husted H, Kehlet H, et al. Effect of knee joint icing on knee extension strength and knee pain early after total knee arthroplasty: a randomized cross-over study. Clin Rehabil. 2012;26(8):716-723. doi:10.1177/0269215511432017

32. Bouhassira D, Villanueva L, Bing Z, et al. Involvement of the subnucleus reticularis in diffuse noxious inhibitory controls in the rat. Brain Res. 1992;595(2):353-357. doi:10.1016/0006-8993(92)91071-L

33. Arendt-Nielsen L, Sluka KA, Nie HL. Experimental muscle pain impairs descending inhibition. Pain. 2008;140(3):465-471. doi:10. 1016/j.pain.2008.09.027

34. Watanabe S, Kakigi R, Hoshiyama M, et al. Effects of noxious cooling of the skin on pain perception in man. J Neurol Sci. 1996;135(1):68-73. doi:10.1016/0022-510X(95)00253-X

35. Niskanen RO, Korkala O, Pammo H, et al. Serum C-reactive protein levels after total hip and knee arthroplasty. J Bone Joint Surg. 1996;78-B:431-433. doi:10.1302/0301-620X.78B3.0780431

36. White J, Kelly M, Dunsmuir R. C-reactive protein level after total hip and total knee replacement. J Bone Joint Surg Br. 1998;80:909-911. doi:10.1302/0301-620X.80B5.0800909

37. Insall JN, Dorr LD, Scott RD, et al. Rationale of the Knee Society clinical rating system. Clin Orthop Relat Res. 1989;248:13-14.

38. Thienpont E. Does advanced cryotherapy reduce pain and narcotic consumption after knee arthroplasty? Clin Orthop Relat Res. 2014;472(11):3417-3423. doi:10.1007/s11999-014-3810-8 


\section{Publish your work in this journal}

The Journal of Pain Research is an international, peer reviewed, open access, online journal that welcomes laboratory and clinical findings in the fields of pain research and the prevention and management of pain Original research, reviews, symposium reports, hypothesis formation and commentaries are all considered for publication. The manuscript management system is completely online and includes a very quick and fair peer-review system, which is all easy to use. Visit http:// www.dovepress.com/testimonials.php to read real quotes from published authors.

Submit your manuscript here: https://www.dovepress.com/journal-of-pain-research-journal 